DOI: 10.12957/demetra.2016.16025

\title{
A cozinha natural como lugar de reencantamento do corpo feminino
}

\section{The natural kitchen as place to re-enchantment of the female body}

\author{
Fábio Lúcio Antunes Guedes' \\ Maristela Oliveira de Andrade \\ 1 Universidade Federal da Paraíba, Programa \\ de Pós-Graduação em Antropologia. João \\ Pessoa-PB, Brasil. \\ Correspondência / Correspondence \\ Fabio Lucio Antunes Guedes \\ fabioloki@gmail.com
}

\section{Resumo}

O presente trabalho visa problematizar a emergência da cozinha natural na contemporaneidade com base em uma etnografia dedicada à corporeidade da prática terapêutica holística (sn. naturalista, integrativa) e sua exigência por uma alimentação natural específica. Apresentamos um pequeno recorte que almeja dar conta da moderna estruturação social culinárica centrada na figura do chef, carnista e masculino, que figura como personagem central no processo histórico de domesticação do paladar, onde há uma naturalização nos valores ligados à proteína animal e uma sensível dessubstancialização da alma feminina, à qual uma cozinha 'inferior' é remetida. Observa-se, através da corporeidade agenciada durante a prática de cura terapêutica, em um bairro da periferia da capital paraibana, a emergência de um vivo processo de construção identitário no qual a experimentação de saladas, o cultivo de plantas medicinais e as práticas de cura assumem papel relevante para a compreensão da constituição de um saber culinárico. Aludimos à condição fenomenológica na qual Comer é, 'imediatamente', Ser, significando o grau mais íntimo no movimento da ecceidade do devir, reconhecendo a prática do vegetarianismo, realizada no centro terapêutico Afya - Centro Holístico da Mulher como um legítimo esforço de um projeto de emancipação do corpo feminino. O recinto culinárico se torna um espaço de reencantamento social, empoderando o corpo feminino e suas práticas: derivadas da articulação de um conhecimento da nutracêutica baseada em plantas.

Palavras-chave: Cozinha natural. Ecofeminismo. Sociedade carnista. Corporeidade. Cozinha moderna. Saúde Holística. 


\section{Abstract}

The present study aims to problematize the emergence of natural cuisine in contemporary times based on an ethnography dedicated to the corporeity of holistic therapeutic practice, and its requirement for a specific natural diet. It is presented a small clipping which aims to account for a modern socially structured culinary context in the figure of the chef who is the central character in the historical process of naturalization of animal protein in the human palate and in the de-substantialization of the female soul. The redefinition proposed by natural kitchen plays an important role in the understanding of complex human body sensitivity to the modern carnivorism, experimented throughout the alternative practices (healing and alimentation) performed at the therapeutic center. The non-governmental institution "AFYA - women therapeutic center" located in João Pessoa, Paraíba, Brasil, symbolizes the effort for recognition of the emancipation of the female body, evidencing cooking site as a special locality for re-enchantment of the female body, based on the legitimacy of vegetarianism as empowering device to resignification of feminine soul.

Key words: Natural kitchen. Ecofeminism. Carnist society. Embodiment. Holistic Health.

\section{Introdução}

A investigação da história da cozinha no mundo ocidental implica a observação do conjunto de fatores fundacionais no que diz respeito à sistematização e categorização científica entre 'ingredientes' e 'produtos' que povoam o estimado recinto que dá lugar à arte de preparação de alimentos. A contemporânea condição de que os usos típicos ou tradicionais de determinados ingredientes já não representam usos (ecológicos ou culturais) isolados, mas, sim, um vivo e complexo processo de hibridização da culinária, culmina com a formação do confuso paladar contemporâneo. "O comedor moderno, literalmente, não sabe mais o que come", atenta sabiamente Claude Fischler. ${ }^{1}$

Esta análise será feita em torno de teóricos críticos que conceituam a modernidade, e a problematizam enquanto condição humana perdida entre a distinção científica das instâncias ontológicas Sociedade/Natureza. ${ }^{2}$ A presente escrita é dedicada à apresentação da Cozinha Natural (CN) em sua pluralidade. Embora costumeiramente denominada como "alternativa", ela certamente possui um campo político muito profundo sobre o qual gostaríamos, ao longo do presente texto, 
abrir teorização sobre um fenômeno específico de conhecimento, e reconhecimento, objetivando ampliar o horizonte de análise inicialmente trazidos por trabalhos que trazem a cozinha sob um contemporâneo recorte de superação epistemológica da dicotomia Natureza/Cultura. ${ }^{3}$

A situação encontrada em campo, de uma 'salgada' busca pela alimentação vegetariana, nos trouxe à formulação de um texto que sai à procura das forças aplicadas na extensão de um corpus social, que é o corpo feminino, em sua dimensão ecológicat: sua constituição e sua relações, na atenção, também, a um desenvolvimento teórico-histórico que é o Feminismo. Preferimos o uso nativo, do termo local (natural), na rejeição do uso do termo "vegetariana", uma vez que a cozinha construída localmente, baseada na dieta de alimentos vegetais e não processados industrialmente, engendra um modo de vida saudável que obedece menos a rígidos receituários ou procedimentos culináricos determinados do que à figuração enquanto um campo em construção aberto às improvisações, às criações e intuições baseadas na leitura atenta, contínua e integral do próprio corpo. Dessa forma, contemplamos o sentido natural de uma forma ampla, e viva, expressa no próprio corpo das cozinheiras-terapeutas com quem realizamos convívio.

Observando as mulheres da Afya - Centro Holístico da Mulher, demos relevância a detalhes e alguns aspectos presentes na adoção da prática naturalista (sn. integrativa, holística,complementar), cuja significação se vê ligada menos a um sistema social-funcionalista do que, propriamente dito, a puras disposições intuitivas desenvolvidas e encontradas em campo, conformadoras de uma sensibilidade autóctone plural e viva. Antes de mais nada, percebo que a construção da cozinha vegetariana não se encerra tão somente ao cumprimento da fruição exclusivamente vegetal, uma vez que, como em grande parte das culturas, derivados de animais e mesmo animais de menor porte serem vistos como aceitáveis, por serem considerados 'leves' (como peixes e aves em nossa cultura). Mais grave, no entanto, tem sido considerar o termo veganismo como referência exclusiva a uma dieta, e não à forma total, moderna e complexa, que configura um habitus da vida humana ocupado em evitar a exploração de qualquer tipo de vida, inclusive a vida animal. Apontamos nosso interesse na compreensão da diversidade de disposições comportamentais, para os quais, como o grupo pesquisado não adota uma dieta com exclusão total dos produtos animais, não se mostrou apropriado o uso dos referidos termos. $\mathrm{O}$ vegetarianismo, portanto, apontamos prontamente, apresenta-se como interessante foco de investigação no campo da Antropologia.

$\mathrm{Na}$ Afya, a nutrição abrange a totalidade das práticas localmente veiculadas. A mera disposição em manter os pés em contato direto com o solo, no momento de cultivo e colheita das plantas medicinais e mesmo durante a preparação da comida (qualifico-as como "cozinheiras de pés descalços"), funda mais que um momento de transcendência 'socioespiritual', atesta a territorialização de um saber culinárico que as atravessa infinitamente, pluralizando-as, e propicia o contínuo renascimento, poiético, dos sentidos oriundos de um feminino em livre formação na arte culinária. Desnaturalizadas, experimentam os caminhos de uma linguagem ousada: não falam mais em carne. 
Podemos situar, figurativamente, de um lado, os alimentos em seu estado natural, e do outro, suas elaborações humanas: comidas que nos ludibriam o paladar e que figuram, como atesta a máxima fischleriana supracitada, como híbridos de difícil identificação. Produzidas industrialmente, proliferam enquanto mercadoria destinada uni(vo)camente à satisfação de um mercado de consumo, objetivado à mitigar o desenvolvimento do sentido (sensível) de comer. ${ }^{5} \mathrm{O}$ corpo, cuja leitura moderna é tripartida entre corpo, mente e espírito, constrói um mundo "humano" de baixa resiliência, débil, estéril, impotente de realizar a mais importante operação de escolha do alimento. O corpo, tripartido, é vítima de uma disputa de poder no terreno no paladar. O sujeito "gastroanômico" sugerido por Fischler emerge nesse quadro social (moderno), retalhado pelo jogo de forças que lhe tomam a corporeidade - que implica toda a degustação, o desfrute em saber discernir o 'bom' do 'mau' alimento. Saber por si só, enquanto ferramenta da mente, não basta, quando a questão paira sobre a questão de sabor, portanto, um lugar inscrito no corpo, remetido à experimentações, elaborações mas também alienação. ${ }^{5,6}$

O entendimento pormenorizado do contexto culinário moderno no qual habitam os comensais da cozinha natural constitui um exercício que pode contribuir para a abordagem da antropologia da natureza, que busca superar modernos dualismos (corpo/espírito, indivíduo/ambiente). Na perspectiva de Csordas ${ }^{6}$ : "a corporeidade é uma questão da carne, compartilhada, mutuamente implicada e nunca completamente anônima”. Aproxima, assim, o sentido de responsabilidade do indivíduo inserido numa cultura alimentar industrializada e globalizada - formadora do atual estado de paranoia social - que se reveste de um ilusória ilimitada onivoria (omni-vorus), e permanece em crise perante uma variedade de alimentos sobre a qual é incapaz de discernir qualitativamente.

Partindo de tais pressupostos, que dizem respeito à Ecologia do sujeito culinárico ${ }^{7}$, buscamos investigar o espaço da cozinha através de uma cotidiana prática de cura, na qual uma sociabilização é diretamente mediada pela produção de gostos específicos, constituintes de um saber plural 'incorporado', mobilizador do corpo como um todo, uma corporeidade que toma em conta o conjunto de afetamentos que compõe uma paisagem culinária específica e moderna, segundo explicita Carlos Alberto Doria ${ }^{8}$ sobre Marcel Mauss e sua abertura para estudos sobre o corpo:

Ele lamentava a ausência de estudos sistemáticos sobre as técnicas do corpo do mesmo modo como, ainda hoje, podemos lamentar a exclusão dessa dimensão no estudo do fazer culinário. Mas é claro que as técnicas podem ser analisadas também em função do seu rendimento ou destreza e acabamos gerando normas de adestramento humano, assim como fazemos com os animais. A transmissão da técnica com vistas ao seu resultado ou destreza inclui uma série de detalhes não observados e por isso seria necessário nos debruçarmos sobre elas, desde a educação da criança. O fundamental é esse longo processo de se empenhar o corpo, como se fosse um simples instrumento ou uma sofisticada ferramenta, na realização de uma ideia ou projeto do comestível. (id, p. 268). 
Remarcamos a identificação de um sentido moderno de mercadoria aplicado ao alimento, marcado, então, por uma destinação em satisfazer um sentido social de consumo em oposição a um sentido (sensível) de comer, segundo Claude Fischler, atento à ecologia que envolve o corpo culinárico moderno.

O alimento, enquanto elemento incorporável do sujeito comedor, atrai especial atenção quando pensado seu poder de ação e controle sobre território do paladar, numa situação em que o organismo humano, tornado débil em sua capacidade de realização de discernimento do 'bom alimento', é vitimizado por uma problemática degustação que condena nossa humanidade irremediavelmente. O sacrifício de animais não-humanos para nossa alimentação terá sempre seu desmerecimento por parte da humanidade do mundo, já adianta um conhecido artigo lévistraussiano sobre a condição bovina nas sociedades modernas. Desde a perspectiva da prática culinária enquanto corporeidade, abre-se uma relação de continumm indivíduo-ambiente ${ }^{9}$ que torna mister a compreensão do fenômeno como pós-social, por assim dizer, adquirindo uma dimensão a partir da qual perguntas mais amplas são dirigidas à Antropologia da Alimentação, abrangendo questões de gênero ${ }^{10}$ e mesmo uma reflexão sobre a historia de relação entre humanos e ingredientes. ${ }^{11}$

A extensa pesquisa de campo toma início com a apresentação do pesquisador como voluntário de um projeto de ação comunitária destinado à construção de uma horta de base agroecológica ligada ao trabalho missionário fundador de uma casa de cura na periferia da capital paraibana. Integrante de uma equipe designada "Projeto Artemísia", essa foi a forma de entrada no campo de pesquisa que findou numa construção de laços de afetividade abrigados pela casa de cura Afya - Centro Holístico da Mulher, sede de convívio e onde se realizavam atendimentos terapêuticos e serviam "comida natural", constituindo o agitado cotidiano das mulheres da organização.

Conversas coletivas durante e entre os almoços, refeições e as práticas terapêuticas, obtivemos relatos sobre o início da projeção terapêutica na vida de cada uma daquelas mulheres, material que serviu de matriz para a interpretação de um mundo resistente às novas corporalidades desenvolvidas no entorno da cozinha afyana. A simplicidade de uma cozinha de pés descalços é simbólico de um processo de libertação dos corpos dessas mulheres cujos horizontes e perspectivas pessoais se viam, em grande parte, entregues à desesperança e à violência engendradas na paisagem social da periferia das cidades.

\section{Cozinha incorporada: formação e encontro de ethos na CN}

A Afya nasceu como grupo de ajuda psicossocial, coordenado por um trabalho missionário que há 15 anos auxilia mulheres na superação de seus problemas pessoais. Atualmente, a instituição é composta por cerca de 20 mulheres, que trabalham na promoção das "terapias natural e holística", na medicina preventiva, na consciência alimentar e no cuidado com o meio ambiente. Atuam 
especialmente na oferta de tratamento médico alternativo na periferia de um bairro metropolitano, atraindo pessoas de estados vizinhos e o fluxo de missionárias e terapeutas holísticos de toda parte do mundo.

Euphrásia Joseph Nyaki (Efu), missionária da congregação Maryknolla e fundadora da instituição, demonstra ser consciente da boa alimentação e sua importância para a constituição da saúde humana. Por meio da prática terapêutica, Efu alia sua formação como bióloga à sua dedicação religiosa e espiritual na difusão de técnicas que levam à sensibilização do corpo enquanto ferramenta-base na percepção e atuação do mundo. O conhecimento trazido por Efu é facilmente reconhecível, demonstrado através do que se pode definir por um conhecimento de corpo inteiro, mobilizado certo modo constante, certo modo sutil, que surge nos momentos de comensalidade, quando nos ensina a sentir o alimento.

Efu sugere postura. Disposição. Fluidez. Uma entonação de palavras, mantras ou frases, com função de purificar o alimento são bem-vindas, como simbólica de um conhecimento georreferenciado: um mapa de pontos e linhas que atravessam o corpo do animal humano, minuciosamente referenciado no interior de pequenos movimentos realizados sob discrição. "Lokah, Samastah, Sukino, Bhavanthub" (anotações de campo, maio 2013).

No convívio da cozinha, no amálgama das conversas, risos, pulos, gritos de alegria que parecem expurgar os maus espíritos de um recinto sagrado, as cozinheiras parecem ganhar força, através de uma forma de contato direto 'com suas raízes' - seus pés em contato com a terra garantem a fluidez dos rios de energia que fluem intermitentes numa cozinha pulsante, viva, onde sentimentos são transmutados em bom alimento. $\mathrm{O}$ alimento não vem pré-fabricado como porções idealizadas de antemão, mas recebem ali seu devido tratamento.

Muita gente nunca comeu o cabinho da beterraba, do nabo, da cenoura, as folhas do brócolis! [...] Aqui a gente aproveita tudo o que pode, né? Lá fora 'eles' jogam tudo fora, se dá pra fazer suco com a casca do abacaxi [...] as ramas da cenoura que são boas para refogar [...] ramas de beterraba, do rabanete, as folhas do brócolis e da couve-flor (anotações de campo, cozinha da Afya, com Dona Lourdes, líder da cozinha, 75 anos).

a Maryknoll é um grupo de três organizações católicas sediadas nos Estados Unidos, são elas: Catholic Foreign Mission Society of America, Maryknoll Sisters of St. Dominic e Maryknoll Lay Missioners. Têm como objetivos: combater a pobreza, proporcionar saúde, construir comunidades e estimular a paz e a justiça social em locais de situação de vulnerabilidade social. Promovem a missão da Igreja Católica através de serviços como: saúde e bem-estar social, agricultura sustentável, desenvolvimento econômico, direitos humanos e formação da juventude cidadã. (Fonte: http://www.maryknoll.org)

b Cito uma pequena oração hindu, a referenciar, através de palavras de poder, as linhas de poder que passam, muitas vezes despercebidas, na forma de códigos, gestos, olhares, que, com certa sutileza, configuram o espaço intersubjetivo. A formação terapêutica empreendida por irmã Efu compreende a formação em Reiki, Terapias Florais, Limpeza Prânica, Constelação Familiar, entre outras. 
São frutas, legumes e verduras, preparadas de maneira simples, cozidas de maneira branda, no vapor ou raladas cruas, segundo uma combinação diversa, que almeja a satisfação de um amplo espectro de exigências dietéticas. A estética do prato também entra como fator fundamental, encantando os visitantes pela disposição simples e livre das rodelas de pepino rodeadas pelas cores da cenoura, da beterraba e do agrião, das formas circulares e das formas mandalas.

A organização da CN conflui para aquilo que são, hoje em dia, considerados consenso, erros comuns da CM: frituras, carne vermelha, alimentos industrializados, temperos, realçadores de sabor e defensores químicos. Os defensores químicos seguem no cardápio moderno sorrateiramente. Igualmente fundamental, e não exatamente óbvio num recinto cauteloso por excelência, o bom humor não costuma ser guardado, e merece o compartilhamento generalizado, numa aparente oposição às prerrogativas assépticas da CM. Aqui, os risos garantem a aura de harmonia que confere, também, um gostinho especial ao alimento no momento da refeição.

Na CN não se dispensam os caules ou folhas que, diga-se de passagem, sequer se encontram disponíveis nas prateleiras de supermercados. As cozinheiras afyanas (lideradas por Dona Lourdes, supracitada) aproveitam o alimento no máximo de seu potencial, dando significação às cascas e restos que antes serviam à lixeira, e agora servem para o preparo de sucos e os talos de verduras verde-escuras, para preencher pães e bolos, feitos com as fibrosas cascas de banana ou as sementes da abóbora. O que não tem mais aproveitamento na cozinha recebe uma preocupada destinação, sendo ora levado por uma das terapeutas, para seus quintais, ora sendo depositado no próprio jardim com a finalidade de se recomporem ao ciclo natural da terra. São operacionalidades propriamente técnicas, que se opõem à calistenia da CM e servem de escancarada denúncia da mecanizada assepsia, do hipercozimento e do desperdício energético total no que tange a uma relação de cuidado com o alimento.

Acompanhar a emergência de tais sujeitos, na companhia e no auxílio no preparo dos cozimentos, nos momentos de recolhimento do material destinado à compostagem, lavando pratos, na identificação de plantas medicinais, no atendimento e na realização das práticas de cura, inseriu o etnógrafo no campo intersubjetivo do desenvolvimento da terapêutica feminina, a partir do qual pudemos dar conta da centralidade do alimento natural no processo de empoderamento no qual elas ganhavam em poder de cura concomitante a um enfrentamento da lógica "tradicional" (local e moderna) de viver, comer, ser, cozinhar.

Na Afya, os comensais (os pacientes e as terapeutas) são acolhidos à mesa já conscientes dos alimentos que devem procurar comer, portando uma lista de alimentos próprios e impróprios, pessoal e intransferível, obtida através de um exame bioenergético proveniente de uma verificação das condições "psico-bio-físicas" do paciente. As dificuldades locais enunciadas pelos comensais, que buscam seguir à risca as indicações do receituário proveniente do exame bioenergético, vão 
ao encontro das dificuldades das próprias terapeutas, girando, sobretudo, em torno de uma certa resistência à prática de comer "carne"12.

A formação de um habitus carnistac se dá em meio a disposições comportamentais reificadas, na forma gostos específicos, diretamente remetidos a um jogo de estruturações de ordem moral, intensificadas no âmbito familiar. Em geral, reveste a exigência de uma dieta 'forte' que confere a própria condição social masculina, ${ }^{13}$ utilizado como justificativa para a adoção de uma dieta que, na modernidade, culmina com a formatação de práticas, técnicas e disposições gerais que legitimam a dietética promovida pelos chefs da haute cuisinne. ${ }^{14}$

O conflito de gênero é latente em campo, visualizado através de muitos depoimentos que contribuíram para a verificação da aceitação/não aceitação da alimentação com base em plantas em seus lares. Os depoimentos revelam dilemas pessoais verdadeiros, pertinentes à formação de um sujeito, cozinheiro e feminino, e a legitimidade de sua expertise. Um complexo contexto de relação de poder paira, pois, sobre o corpo da mulher: separada entre vivenciar seu cotidiano, no qual atualmente se encontra 'livre', ou 'encontrada' segundo elas mesmas dizem e o passado de sofrimento, resistência e luta num ambiente desfavorável ao espontaneísmo do espírito feminino. Hoje se veem amadurecidas, empoderadas a partir de um grupo de ajuda mútua que lhes dá voz e forma uma equipe terapêutica eficiente que, todavia, enfrenta uma áspera indisposição mesmo a formas menos radicais de vegetarianismo, como a praticada na Afya. Segundo Adams ${ }^{13}$

Para as mulheres numa cultura patriarcal, surgem preocupações adicionais. Para nós, somos as devoradas e as devoradoras. Somos as consumidas e as consumidoras. Somos aquelas cujo estômago não dão ouvidos e somos aquelas que procuram ser ouvidas de dentro de um estômago que não dá ouvidos. Comer animais atua como espelho e representação de valores patriarcais. Comer carne é a re-inscrição do poder masculino em toda refeição. A visão patriarcal não enxerga o corpo fragmentado de um animal morto, mas uma comida apetitosa. Se nosso apetite re-inscreve o patriarcado, nossas ações com respeito aos animais reificará ou desafiará essa cultura estabelecida. Se a carne é símbolo da dominância masculina, então a presença da carne pro-clama o desempoderamento da mulher (id, p. 24, trad. e grifo nosso).

A perspectiva ecofeminista ${ }^{15}$ ilumina a descrição de um contexto moderno que muito se aproxima da condição local de enfrentamento das cozinhas (moderna e natural), que tem como arena de disputa o paladar e, como abono, a conquista do corpo feminino. Sujeito social dedicado à cozinha do cotidiano, as relações de força que operam sobre seus corpos é vivenciada, aparentemente, num duplo sentido: no âmbito ‘interno', na disputa de gostos na formação de seu

c Carnismo é um termo utilizado como referência a toda prática relacionada ou derivada da alimentação baseada no consumo de carne animal, usualmente compreendido como uma ideologia encarregada de prover justificação moral para o consumo de produtos derivados da exploração animal (cf. ADAMS, 1990, FELIPE, 2012). 
próprio paladar, e no âmbito social, onde ela é mulher, mãe e esposa e uma predileção carnívora atravessa seus corpos segundo uma hierarquização dos gostos remetidos aos chefs da modernidade.

A partir da experimentação corpórea de um estado limítrofe, entre uma identidade de mulheres donas de casa de um lado, e uma nova identidade, de terapeutas holística, de outro, a ideologização masculina da CM contextualiza os valores e disposições sociológicas presentes em seus lares, parece oferecer não muito além de uma profunda indisposição para com as descobertas (ecológicas e femininas) realizadas em seu processo de maturação terapêutica. Conservadores quanto às mudanças alimentares, os comedores da CM exigem a presença da carne animal através de um dispositivo de controle da prática culinária, imediatamente remetido ao controle do corpo de suas companheiras, cozinheiras do cotidiano. Segundo Carol Adams:

Comer carne é a maneira mais frequente de interação com animais. O açougue é a quintessência da legitimação do ato de comer carne. Ele legitima um literal desmembramento dos animais concomitante à proclamada distinção intelectual e emocional dos desejos dos animais. A carnificina como paradigma proporciona, também, entrada para o entendimento de uma profusão de sobreposições culturais imagéticas (id, p. 66, trad. nossa).

O controle do corpo feminino parece, pois, legitimado por uma prática reificada, um habitus que nega a descentralização da carne enquanto alimento, numa consequente exigência da cozinheira de submissão a um sistema essencialmente violento ${ }^{16}$ distanciado da prática relacional, responsável ${ }^{17}$ sensível, construído sobre uma crítica mais profunda da reflexividade e da ressignificação do quantum de vida nos humanos e não humanos ${ }^{18}$ - que na Afya o experimentam (ou melhor, internalizam) entre as folhas, flores e frutos do jardim medicinal que elas cuidam. É o princípio do cuidado, e não da exigência que toma palco. É a satisfação de um desejo sincero, ligado às percepções que são criadas enquanto se cozinha e não manutenção de uma falta, dada como estrutural.

Manter o discurso de deslegitimação da prática vegetarianista desloca, pois, o próprio campo de possibilidade de devir feminino, que ali se realiza através de um intenso movimento íntimo, nutriz, reflexivo, deuteroaprendizado ${ }^{19}$ condenado à satisfação da condição de encontro da cura e da emancipação de um estado anômico, que caracteriza a cozinha dos chefs, que se popularizou, e se tornou convencional, e essencialmente doente. Seguindo os relatos das cozinheiras sobre seus maridos e família, foi através da expressão do trabalho delas que seus maridos se animaram, também, a buscar o tratamento terapêutico. Deixando de ser anômicas, reencantaram, por decurso, a seus maridos. A Afya hoje atende a homens e mulheres independentemente, havendo, todavia, uma procura muito maior por parte do público feminino.

Resumidamente, aqui, introduzimos nossa pesquisa na exposição dos motivos encontrados em campo que impulsionaram a perspectiva teórico-metodológica adotada. Tais motivações dizem respeito à atenção com a forma com que o aprendizado é incorporado: segundo um continuum 
na formação culinárico-terapêutica, essencialmente ligada à "atenção da atenção", por assim dizer, articulando a experiência de exploração do mundo material ao desenvolvimento de uma sensibilidade nova, e inevitavelmente ligada ao resgate da alma feminina.

A participação pessoal nos cursos de formação oferecidos pela instituição (Terapia Bioenergética, Fitoterapia e Alimentação Natural) serviu para uma experiência crescentemente próxima de um conhecimento profundamente exigente da sensibilização. O processo de 'formação natural', mediado pela instituição, realiza-se mediante uma dedicada calibração do corpo, no uso de um vocábulo comum entre elas, terapeutas-cozinheiras, que possuem a atenção como ferramenta essencial para a acurácia na leitura de um mundo repleto de sinais, marcas e indícios significativos - mundo esse invisível aos olhos do pesquisador-neófito, inicialmente insensível.

Profundamente orientadas a uma atenção reflexiva, das sensações corporais e dos estados emocionais 'internos', as terapeutas criticam com firmeza um 'conhecimento por conhecimento', isto é, sem uma atividade prática, como uma dedicação no vazio. Creem que, somente por meio de um atento engajamento no mundo, no atendimento de pacientes, na troca constante de abraços, de olhares, na dedicação à enunciação de palavras 'de poder' ou sentindo seus pés em contato direto com o solo, desenvolvem satisfatória estabilização para a tradução dos sinais de um mundo eloquente. ${ }^{8}$ Uma atenta observação aos sinais do mundo permite a elas, ou melhor dizendo, conduze-nas ao discernimento das mensagens importantes num ambiente vivo, rico em informações, como sugere Ingold ${ }^{5}$

Aprender a enxergar, portanto, não é questão de aquisição de esquemas para uma construção mental do ambiente, mas adquirir habilidades (skill) para um engajamento perceptual efetivo para com seus constituintes, humanos e não-humanos, animados e inanimados (id, p. 55, trad. nossa).

Como um processo contínuo de reelaboração de si, num ativo envolvimento com o meio, a nutrição representa uma literal forma de construção identitária, mobilizando integralmente (mente e corpo) no campo da anomia fischleriana - condenada condição do comedor-consumidor moderno, nutrido por um chef carnista. Atentas e dedicadas a se constituírem enquanto "boas comedoras", quer dizer, capazes de calibrar seus corpos de modo a possibilitarem-se em distinguir o bom/mau alimento. "Aproximar subjetividades", ${ }_{17}^{17}$ aqui, proporciona um alcance ecológico mais amplo, alçando rompimento com barreiras ontológicas matriciais de uma percepção antropológica tradicional e antropocêntrica. Para melhor compreender a nova tendência, de virada epistemológica, que aqui recai como uma exigência ecológica do campo da alimentação, da relação de comer ao outro, a concepção de ecologia de Ingold ${ }^{20}$ nos parece apropriada:

Vou explicar como o meu tipo de ecologia difere de [...] "reconhecer apenas organismos humanos no seu ambiente material (seja ele natural ou artificial) e enfocar estados e 
processos mentais individuais desses organismos e causas e efeitos físico-ambientais dessas coisas mentais" [...] Em contraste, uma abordagem propriamente ecológica, no meu modo de ver, é aquela que trata o organismo-no-seu-ambiente não como um compósito de fatores internos e externos, mas como uma totalidade indivisível. Esta totalidade é, na verdade, um sistema desenvolvimental, e a ecologia lida com a dinâmica de tais sistemas (idem, p. 25, em nota de rodapé).

Desenvolvido a partir de uma interação pessoal e (inter)subjetiva, de articulação de um corpo específico imerso num ambiente vivo, o gosto figura como uma qualidade intrínseca às próprias condições de formação de um corpo. Diretamente responsável, oferece um novo quadro de interpretação à disposição do paladar carnista operado enquanto uma espécie de habitus, antecedendo a própria escolha racional do indivíduo.

Essa dimensão inconsciente do "habitus" é que opera na explicação da resistência à mudança da dieta alimentar. Segundo Doria ${ }^{20}$, a CM estruturada segundo sua própria mecanicidade implica protocoladas exigências técnicas, como clarear, fatiar, sufocar (privar de oxigênio), congelar, banhar, cobrir, fritar, molhar, marinar e escaldar:

são comandos obrigatórios sobre o cozinhar. Deles está abstraída a intenção do "cozinhar para o outro", a intenção de seduzir, de aproximar subjetividades, o que só pode ser inscrito no produto desse conjunto de ações pelo comando finalista do chef(id, p. 216, grifo nosso).

Protagonista da criação culinária na CM, o chef encarna de modo evidente o processo de adestramento corpóreo desenvolvido a partir da profusão de produtos alimentares, substancialmente constituídos da patriarcalizada configuração que desqualifica as cozinheiras do dia-a-dia ${ }^{8}$. A naturalização do paladar humano é consideravelmente nutrida pela reificada projeção carnista observável nas comidas preparadas pela CM, na averiguação de um carno-centrismo socialmente ligado à manutenção de um ethos masculino de virilidade ${ }^{16}$ :

Comer carne tem sido a norma dominante há séculos no mundo ocidental. É da natureza das normas dominantes serem aceitas inquestionavelmente. Além disso, quando pessoas se tornam vegetarianas, são sempre questionadas para explicar sua escolha dietética [...] O carnivorismo, assim como a heterossexualidade, é visto como um institucionalização compulsória que é imposta, organizada, propagandeada e mantido a força com o intuito de manter direito ao acesso de uma sociedade dominantemente masculina a não-humanos e sua carne [...] assim como mulheres são vistas como incompletas (no sistema heteronormativo) na ausência de um homem, também são, as comidas vegetarianas, vistas como incompletas sem a adição da carne. [...] Comer carne é uma atividade biológica, mas é também uma prática incutida na cultura e codificada com significados simbólicos (id, p. 329-330). 
Na Afya, uma primeira imersão nos induziu a pensar que os maridos das terapeutas eram os responsáveis pela manutenção da predileção carnista através de uma explícita exigência pelo "alimento forte". O gosto pela carne, no entanto, também era expressão de um afeto compartilhado por elas mesmas, numa explícita e consciente atitude 'incoerente' sob a perspectiva da formação terapêutico-naturalista. A constatação desta aparente ambiguidade exigiu uma retomada na interpretação da formação do paladar local, considerando a presença de gostos num sistema em disputa, inscrito no corpo das terapeutas, o que proporcionou a figuração de um contexto em que a prática carnista funciona, antes de mais nada, anterior e posterior à racionalização de suas próprias ações. A cozinha afyana abre espaço, pois, para a reconstituição da alma feminina ex-situada do recinto culinárico, habilitando prática natural e feminina na livre experimentação e ressignificação do próprio terreno de constituição de alteridade, seus corpos, os próprios mediadores no horizonte de relações de sociabilidade trans-humana, a partir de uma cozinha criativa, idiossincrática, dedicada ao outro como forma de autodescobrimento e em expansão, afinal, segundo Carlos Alberto Doria ${ }^{20}$ :

A cozinha feminina, doméstica, é a cozinha das idiossincrasias, das especificidades, pois se cozinha "para o outro", que é sempre um outro concreto, conhecido em sua subjetividade e, portanto, singular. A cozinha de mães e avós é de valor incontestável [...] cozinhar é muito mais saber empenhar o corpo no trabalho culinário [...] do que "seguir" qualquer receita, pois esta jamais substituirá sua destreza particular ao buscar um resultado específico e do agrado para quem cozinha (id, 220-221).

A presente seção aponta para um intransigente fardo epistêmico-sociológico carnofalocêntrico moderno, que atesta nada menos a histórica intromissão do chef no recinto culinárico. Sob a perspectiva da corporeidade, surge uma proposta paradigmática para pensar o fenômeno social do corpo como elemento síntese, em que se articulam 'sujeito' e 'objeto', 'conhecimento' e 'autoconhecimento', 'eu' e 'outro', em prol de um movimento de "encarnação" cultural que constitua os seres humanos numa "ontologia que dê primazia aos processos de formação ao invés do produto final, e aos fluxos e transformações dos materiais ao invés dos estados da matéria”.

Esta questão reaparece num conjunto de diferentes teorizações que convergem na busca de caracterizar a emergência do sujeito ecológico e sua potencialidade diferenciadora a partir de suas formas de relacionamento no mundo. Torna-se importante, portanto, a apreciação desse modo específico de fazer cozinha, enquanto um processo engajado de experienciação do mundo. A gastronomia possui, por excelência, a inata condição de agregar os sentidos que, fora do prato, transformam-se num "universo de categorias", ${ }^{20}$ dos quais falta, todavia, uma merecida investigação, possível através da perspectivação de um "universo feminino", representado como uma poderosa ferramenta heurística, que nos permita a experiência de um pensar atento ao que pode não ser bom para comer. 


\section{A insuficiência ecológica da Cozinha Moderna}

Inspira-nos a presente redação uma forma de Antropologia dedicada à dimensão dos afetamentos do campo antropológico enquanto uma experimentação da vida, mais ou menos indistinta se biológico ou cultural. Como biólogo de formação, encarei o árduo exercício de reconhecimento e despimento de uma forma de saber naturalizadora das formas de vida. ${ }^{2,7} \mathrm{Na}$ permissão de um reencantamento laborioso, remetido à experiência de (re)apresentação às formas naturais (minerais, plantas e animais) que antes pareciam tão íntimas, objetivamos contribuir para a melhor apreensão possível das motivações que levam mulheres de uma comunidade periférica de uma cidade paraibana a adotar um sistema cosmológico que trata indistintamente a ontologia que distancia a matéria viva da inerte, o mental do espiritual, e se lança à compreensão unívoca de um sentido de vida, apontando para um tipo de "vitalismo" filosófico no qual a vida é imanente às coisas do universo, ao qual Ingold ${ }^{9}$ trata de enaltecer. Ainda segundo este autor, sobre a ontogenia dos organismos terrestres ${ }^{18}$ :

A árvore é um objeto? [...] Onde termina a árvore e começa o resto do mundo? [...] se decidimos que os insetos que vivem na casca pertencem à árvore tanto quanto a própria casca, então não há razão para excluirmos seus outros moradores, inclusive o pássaro que lá constrói seu ninho ou o esquilo para o qual ela oferece um labirinto de escadas e trampolins. Se consideramos que o caráter dessa árvore também está em suas reações às correntes de vento no modo como seus galhos balançam e suas folhas farfalham, então poderíamos nos perguntar se a árvore não seria senão uma árvore-noar (id, p. 28-29, grifo nosso).

Tal exame constitui a porta de entrada para uma complexa perspectiva de mundo na qual a vida parece atravessar nossa incólume constituição humanista. "Nada, para dizer a verdade, nos é mais inacessível do que essa vida animal da qual somos resultantes", reitera Bataille em sua Teoria da Religião. Adentrar um mundo de relações de ‘sociabilização intraespecífica', etnografada entre as plantas de um jardim de ervas medicinais, nutrido por uma forte revalorização da substantiva de uma pluralidade de coisas (seres inanimados, plantas e animais não humanos) no que diz respeito ao reconhecimento de sua participação em "nosso" mundo social, isto é, exclusivamente humano.

Marvin Harris ${ }^{21}$ já chamava a atenção para o fato de que os hábitos alimentares possuem dimensões culturais importantes, apesar de operar sobre a distinção entre razões econômicas e ecológicas, na consideração de cálculos relativos a custos e benefícios que estão por trás de preferências e evitações a alimentos específicos, incluindo as consequências a longo prazo daquele tipo de produção alimentar. Segundo ele, "os alimentos não são somente fonte de nutrição para a maioria, como também riqueza e poder para uma minoria”. E se Harris destaca o papel dos produtores de alimentos e seus processos agrícolas, Mary Douglas, ${ }^{22}$ ao abordar as interdições 
alimentares a partir do uso estrutural-classificatório de pureza e poluição, pode ajudar a pensar nas preferências e proibições no campo da CN.

Contextualizar a CN significa atentar para a forma como a culinária moderna traz, sob sedutores invólucros silenciadores da real composição nutricional dos alimentos, expostos sob a fetichizada disposição de carboidratos, açúcares e proteínas - ingrediente e produtos, típicos da CM, movidos por uma unívoca destinação fisiológica: a adocicação do paladar. O paladar, pois, inscreve-se nos corpos humanos por intermédio de um litigioso contexto das emoções agenciadas por gostos específicos, ligados à memória cultural do indivíduo. Retomando os estudos de Claude Fishler, ${ }^{23}$ lembramos:

A estratégia comercial moderna não repousa mais somente na sedução ou intimidação operada pelo vendedor, ou pelos abusos publicitários, mas sobre um silêncio cuidadosamente orquestrado [...] O novo comedor-consumidor não sabe mais como reconhecer o comestível do não-comestível, acabando por dificilmente reconhecer a si mesmo (id, p. 205-206, trad. e grifo nossos).

Claude Fischler, ao propor um recorte sociológico das competências humanas entre Comedores ou Consumidores, abre caminho para uma clara disputa de poder territorial onde a conquista do paladar é o que está em jogo. Se o sujeito comedor sugere a figura de um 'consumo consciente', pensamos na ideia do consumidor como um tipo de comedor raso, de paladar viciado, iludido, alienado por produtos industriais - morto, vazio de sentido nutricional. Transformados em "consumidores puros"' da CM, uma profusão de corpos são desumanizados, reduzidos pela dietética dos padrões nutricionais que naturalizam o paladar humano.

A CM, essencializada em relações matemáticas da nutrição molecular, ${ }^{20}$ contribui para a perda da noção do próprio e do impróprio no ato mesmo em que engendra, goela abaixo, comidas congeladas, pré-cozidas, pré-assadas, enlatadas, imediatas, incorporando-se à relutância de uma conscientização, como ocorre na Afya, onde uma clara disputa parece opor formas orgânicas, saudáveis, ecológicas, verdes, nesse momentum de construção sociológica, forrando porcentagens da dieta de um ser humano ideal. Gostos fictícios, objetivados à inscrição sobre o palato humano, contribuem para a naturalização de uma nutrição numérica, repartida entre açúcares, gorduras e desejadas quantificações de "ferro", "micronutrientes", "fibras", "aminoácidos", "vitaminas" e "proteínas". São, todavia, incipientes as pesquisas no âmbito sociológico que buscam evidenciar a relevância da formação do paladar do referido "comedor moderno", na consideração das reações que sejam da ordem de sua própria formação enquanto Sujeito Ecológico (sn. orgânico, integral, natural). Como alertam estudos já considerados clássicos como as investigações de Mintz, ${ }^{24}$ sem todavia atentar para a virada ontológica emergente da relação comedores-ingredientes como realmente constitutivos, sujeitos atuantes na vida social humana: 
Comidas cotidianas, prosaicas, que tendemos a considerar comuns, escondem histórias sociais e econômicas complexas. O lugar da proteína vegetal no futuro do mundo pode se tornar um problema político de primeira ordem (id, p. 39).

A desnaturalização de um habitus carnista reforça a prática da alimentação natural enquanto constitutiva de uma experiência na qual viver de 'improviso' representa uma forma autêntica de enfrentamento das formas relacionais "estáveis" que priorizam o estado de vida de humanos sobre a não humanidade, segundo Ingold ${ }^{3}$ :

o que o cozinheiro, o alquimista e o pintor fazem não é impor forma à matéria, mas reunir materiais diversos e combinar e redirecionar seu fluxo tentando antecipar aquilo que irá emergir. [...] as cerâmicas não são mais estáveis que corpos; são constituídas e mantidas no lugar dentro de fluxos de materiais. Deixados ao léu, os materiais fogem do controle. Potes se quebram, corpos desintegram. Esforço e vigilância são necessários para manter as coisas intactas, sejam elas potes ou pessoas. [...] (id, p. 36, grifo nosso).

A perspectiva adotada por Ingold permite criar uma compreensão da prática alimentar ‘alternativa' como uma real reformulação da própria motivação gastronômica, através de uma percepção de nutrição levada a sério, proximal, e apoiada sobre uma subjetividade coletivamente vivenciada através de práticas corporais ligadas a uma relação sócio-trófica entre plantas, animais e humanos. A adoção de tal reposicionamento na relação entre sujeitos retoma o projeto de nutrição moderno numa processual tomada de reconhecimento, numa aparente inversão energética na cosmo-ecologia local, que organiza entre humanos e não humanos imersos num ambiente-relacional.

\section{Considerações finais}

E o final de semana, minha gente, como foi? - Eita, foi bom, Fabinho e o seu? Teve uma festa [...] fizeram uma galinhada ... ai, você não gosta, né?

(Respondo rindo) tudo bem. - Mas era daquelas criadas solta, 'capoera', menos mal né, elas tiveram mais liberdade...

Mas vocês não fazem galinha aqui? - Não, não, aqui é mais natural (risos)

(caderno de campo, na cozinha da Afya, maio 2013).

Acolhidos por uma cozinha realizada segundo um profundo despertar da sensibilidade nas formas de tratamento e consideração para com 'o outro alimentar', os comensais afyanos, envolvidos por um melhor aproveitamento dos alimentos, figuram como críticas vivas de uma verdadeira 
falta de intimidade por parte da CM, engessada em sua predisposição industrial em transformar animais e plantas em alimentos sem vida.

Dispensável dizer que não são incomuns o imediato estranhamento por parte dos pacientes, quando da constatação da aparente restrição dietética. Sem que percebam de início que tal proposição significa, em verdade, a ampliação de uma oferta alimentar no sentido que defendemos até o presente momento, aos poucos aprendem a construir laços realmente afetivos e a confiar em certos sentidos, como defende Dona Lu quando diz que "a cura não está nas plantas", na defesa sobre a importância dos alimentos orgânicos, "mas a importância está na forma de cultivá-las, de se relacionar com elas". As plantas possuem um poder de cura quando ingeridas regularmente na forma de alimentos livres de agrotóxicos, uma vez que são regadas com dedicação e com amor.

Numa tentativa de representar a cosmoecologia local, oferecemos o seguinte esquema, em que as plantas representam o fundamento da recomposição energética:

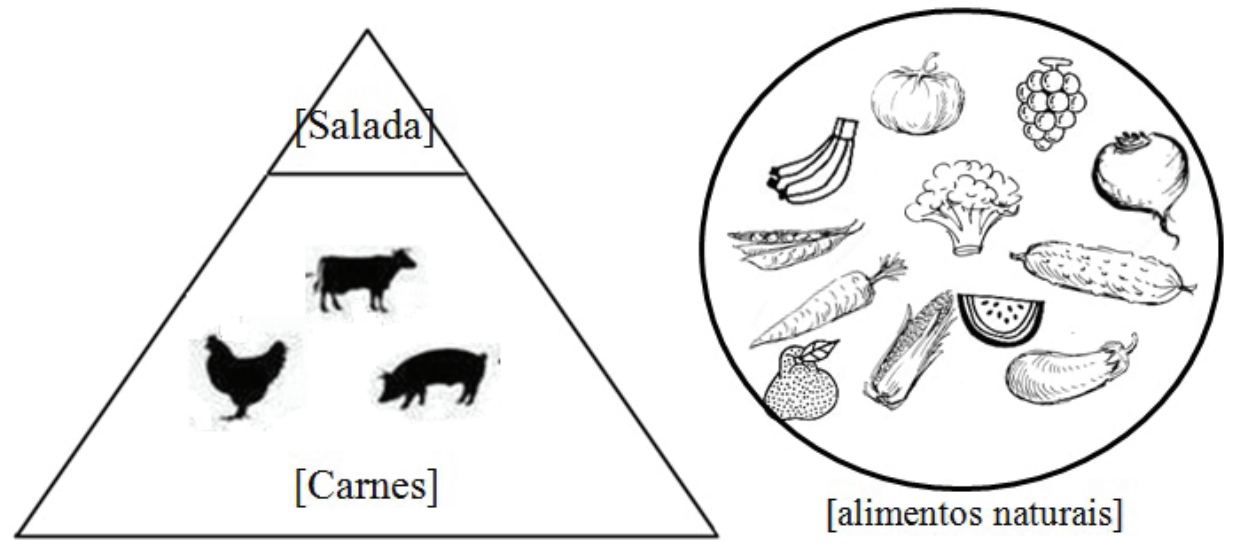

Figura 1. Representação imagética da CM e da CN: à esquerda modelo hierárquico que valoriza a dieta da carne; e à direita, modelo não hierárquico dos alimentos naturais.

A figura acima expressa uma sugestão imagética representativa da estruturação dietética convencionada pelas diferentes cozinhas. De um lado, a estrutura hierárquica da CM, baseada na representação da carne, na qual a proteína animal constitui a base de uma alimentação objetificada nas mãos de um chef. Do outro, uma representação não hierarquizada de alimentos naturais, um campo aberto, inespecífico e exigente de intimidade, aproximação e improviso, correspondente a um processo sócio-histórico de desnaturalização da proteína animal do espírito humano, permitindo 
a livre emergência de um paladar aberto às relações, baseado na "cozinha para o outro", ${ }^{20}$ isto é, dedicada, atenta à intersubjetividade (a qual, indicamos ao longo do presente artigo, merece ser contemplada à luz da Ecologia, e sua conceituação -o caráter ambiental- no campo antropológico).

Na CN local, a fruição alimentar se baseia na exploração criativa de um vasto campo de possibilidades vegetais, muito em parte desconhecido do paladar dos pacientes em função da 'pre-conceituosa' indisposição para com as folhas, ramos e demais partes, porções de alimentos recortadas e dispensadas pela CM. Enaltecemos a importância da exposição ora presente, de um vegetarianismo em processo, em movimento, localmente construído, atento para uma perspectiva que vai além de meras escolhas culinárias e que opera buscando a ilustrada inversão de valores, das plantas sobre os animais, representando, para o corpo dos comedores da CM, um risco à fisiologia humana que toda prática vegetarianista tende a colocar à prova.

Buscamos acompanhar a problematização proposta pelas próprias mulheres, em seu oficioso trabalho culinárico, sobre a ordinariedade do papel das plantas na construção do mundo moderno, renegadas à categoria de "salada”, e da instituída naturalização do apetite humano, inconsequente quanto à formação segundo plano sociológico de consumidor fishleriano.

A histórica exclusão do corpo feminino da CM parece acentuar o conflito existente em torno dos processos de cura legitimados pela $\mathrm{CN}$ no momento em que a prática vegetariana figura um medo social de desrespeitar a construída naturalidade humana em comer carne. Os "laboratórios nutritivos" de Augusto Comte, responsáveis pela elaboração de “compostos orgânicos necessários à nossa subsistência" ${ }^{25}$ denotam um alto grau de naturalização carnista no espírito humano hodierno.

A emergência de processos de empoderamento mediante um redimensionamento cosmoecológico, no qual as plantas passam a fundamentar o sentido de 'alimento forte,' contribui para a pertinência da apreciação da temerária prática vegetarianista no âmbito de uma profunda literatura filosófico-antropológica dedicada à problemática distinção ontológica Natureza/ Cultura, que fornece coesão ao pensamento moderno ocidental. A pertinência do uso culinário de ingredientes de origem animal (carne e derivados) contamina a $\mathrm{CN}$ de diferentes formas, as quais buscamos dar peremptório tratamento intelectual, à guisa do que Lévi-Strauss ${ }^{25}$, à propósito da epidemia da vaca louca, refletiu sobre o que seria uma moderna ameaça à constituição humana:

esses fenômenos perturbam e perturbarão de forma profunda as condições de vida da humanidade, anunciando uma nova era na qual se instalaria, em continuidade, esse outro perigo mortal que seria agora a alimentação carnívora [...] apostamos que o apetite pela carne nem por isso desaparecerá. Sua satisfação se tornará apenas uma ocasião rara, custosa e cheia de risco [...] A carne figurará no cardápio em circunstâncias excepcionais. Será consumida com a mesma mistura de reverência piedosa e de ansiedade que, segundo os antigos viajantes, impregnava as refeições canibais de certos povos. Em ambos os casos, trata-se ao mesmo tempo de comungar com os antepassados e de incorporar, com seus riscos e perigos, a substância de seres vivos que foram ou se tornaram inimigos (id, p. 215-216). 
O futuro sombrio da dieta da carne bovina deve ainda alimentar a discussão contemporânea no que diz respeito aos riscos de uma "saúde ambiental", envolvendo humanos e não humanos de maneira 'desnaturalizada', não hierarquicamente. Crítica da inconsequente naturalização do paladar humano como fundante da atual anomia dos modernos consumidores-comedores, conforme se estendem sobre esse assunto linhas de estudo ecofeministas e também seguindo a orientação de estudos dedicados à alimentação animal, ${ }^{26}$ nos quais a idealização alimentar revela implicações de fundo que dizem respeito à história evolutiva de animais não humanos, esfriando as novas demandas de construção humanística e libertária que incorporam a dimensão ecológica no mundo antropocêntrico moderno.

Enfim, o comedor natural recria a possibilidade de sensibilização de paladar humano através da aproximação ontológica dos seres que compõem a cosmoecologia humana, abrindo propostas para a constituição de um campo que demanda, todavia, maiores e mais amplas investigações sobre as construções socioculturais que marcam o dissabor da exploração da vida no contexto culinárico moderno.

Agradecemos aos demais trabalhos que tratam da questão vegetarianista, merecendo especial referência, pelo caráter introdutório ao tema, o de Elaine de Azevedo. ${ }^{27}$ Apontamos, no entanto, para uma renovada tipologia, em termos de referencial bibliográfico, com forte problematização crítica no que diz respeito à forma de tratamento teórico-epistemológico dado à culinária na Antropologia, pluralizando o referencial teórico dedicado a tal especificidade.

\section{Agradecimentos}

Agradeço imensamente às terapeutas da AFYA - Centro Holístico da Mulher, pela colaboração, sobretudo a Efu Nyiaki, missionária-chefe da instituição, quem muito me ensinou os caminhos da fruição vegetal;

Agradecemos também à CAPES, pelo auxílio e incentivo no fornecimento da bolsa de estudos dedicada à formação da carreira de antropólogo.

\section{Referências}

1. Fischler C. Gastro-nomie et gastro-anomie. Communications: 31(1):189-210, 1979

2. Latour B. Jamais fomos modernos: ensaio de antropologia simétrica. Rio de Janeiro: Editora 34; 1994.

3. Ingold T. Trazendo as coisas de volta à vida: emaranhados criativos num mundo de materiais. Horiz Antropol v. 18(37):25-44, 2012. 
4. Ingold T. The perception of the environment: essays in livelihood, dwelling and skill. London: Routledge; 2000.

5. Fischler C. L'homme omnivore. Paris: Editions Odile Jacob; 1990.

6. Csordas T. Fenomenologia cultural corporeidade: agência, diferença sexual, e doença. Educação 36(3):292-305, 2013.

7. Steil CA, Carvalho ICM. Epistemologias ecológicas: delimitando um conceito. Mana v. 20 (1):163183, 2014.

8. Dória CA. Flexionando o gênero: a subsunção do feminino no discurso moderno sobre o trabalho culinário. Cadernos Pagu (39):251-271, 2012.

9. Ingold T. Epilogue: towards a politics of dwelling. Conservation and Society 3(2):501-508, 2005.

10. Counihan CM, Kaplan SL, editores. Food and gender: identity and power. Amsterdam: Taylor \& Francis, 2005.

11. Montanari M, Silva VP. Mundo na cozinha: história, identidade, trocas. São Paulo: Senac Editora; 2009.

12. Felipe ST. Galactolatria: mau deleite: implicações éticas, ambientais e nutricionais do consumo de leite bovino. São José: Ecoânima; 2012.

13. Adams CJ. The sexual politics of meat: a feminist-vegetarian critical theory. New York: Bloomsbury Academic; 2014.

14. Kheel M. Vegetarianism and ecofeminism: toppling patriarchy with a fork. In: Sapontzis

15. SF. Food for thought: the debate over eating meat. Amherst, NY: Prometheus Books, 2004.

16. Warren KJ. Ecological feminist philosophies: an overview of the issues. Ecological feminist philosophies. Bloomington: Indiana University Press; 1996.

17. Haraway, D.. A partilha do sofrimento: relações instrumentais entre animais de laboratório e sua gente. Horizontes Antropológicos, v. 17, n. 35, p. 27-64, 2011.

18. Ingold T. Repensando o animado, reanimando o pensamento. Espaço Ameríndio v. 7(2):10-25, 2013;

19. Ingold, T. Da transmissão de representações à educação da atenção. Educação, v. 33, n. 1, 2010.

20. Doria CA. A formação da culinária brasileira. São Paulo: Tres Estrelas; 2014.

21. Harris M. Bueno para comer: enigmas de alimentación y cultura. Madrid: Alianza; 1999.

22. Douglas Mary. Pureza e perigo. São Paulo: Perspectiva; 1976.

23. Fischler, C. La symbolique du gros. Communications, v. 46, n. 1, p. 255-278, 1987.

24. Mintz S. Comida e antropologia: uma breve revisão. Associação Nacional de Pós-Graduação e Pesquisa em Ciências Sociais v16(47):31-41, 2001;

25. Lévi-Strauss C. A lição de sabedoria das vacas loucas. Estudos Avançados 2009; 23 (67):211-216. 
26. Lewgoy B, Sordi C. Devorando a carcaça. Contracozinhas e dietas alternativas na alimentação animal. Anuário Antropológico II:159-175, 2012;

27. Azevedo E. Vegetarianismo. Demetra: Alimentação, Nutrição \& Saúde, 8(Supl. 1):275-288, 2013.

Recebido: $14 / 4 / 2015$

Revisado: 21/10/2015

Aceito: 08/3/2016 